06.1

\title{
Закономерности трения многоуровневых композиционных материалов, содержащих высокодисперсные частицы фуллереновой сажи
}

\author{
() И.А. Кобыхно ${ }^{1}$ Ф.А. Юнусов ${ }^{1}$, А.Д. Бреки ${ }^{1}$, О.В. Толочко ${ }^{1}$, А.Г. Кадомцев ${ }^{2}$ \\ ${ }^{1}$ Санкт-Петербургский политехнический университет Петра Великого, Санкт-Петербург, Россия \\ ${ }^{2}$ Физико-технический институт им. А.Ф.Иофрфе РАН, Санкт-Петербург, Россия \\ E-mail: ilya.kobykhno@gmail.com
}

Поступило в Редакцию 4 сентября 2020г.

В окончательной редакции 14 ноября 2020 г.

Принято к публикации 15 ноября 2020 г.

Представлены результаты трибологических исследований углепластиков, наполненных наночастицами фуллереновой сажи. Показано, что при увеличении содержания фуллереновой сажи до 4 mass\% коэффициент сухого трения фактически не меняется, а увеличение силы трения происходит за счет сил межмолекулярного притяжения, равнодействующая которых монотонно увеличивается.

Ключевые слова: композиционные материалы, углепластики, фуллереновая сажа, трение, износ.

DOI: 10.21883/PJTF.2021.05.50668.18540

Благодаря уникальным механическим свойствам полимерные композиционные материалы (ПКМ), наполненные непрерывными стеклянными и углеродными волокнами, начиная с середины XX века нашли широкое применение в качестве конструкционных материалов [1]. В настоящее время все большее внимание привлекает синтез многоуровневых ПКМ, содержащих углеродные нанодобавки, такие как углеродные нанотрубки, фуллерен, графен, фуллереновая сажа и т.д. Показано, что такие добавки существенно увеличивают прочность, жесткость, вязкость разрушения, в основном за счет улучшения адгезии между волокном и полимерной матрицей [2], так как межслоевое разрушение является одним из основных механизмов разрушения композиционного материала. Целый ряд работ показывает положительное влияние введения углеродных нанотрубок, фуллеренов и фуллереновой сажи $(0.4-4 \%)$ в полимерную матрицу на механические свойства ПКМ [3-6]. Таким образом, многоуровневые композиционные материалы, полученные путем введения углеродных наноструктур в полимерную матрицу, фактически являются новым классом ПКМ, обладающих повышенными механическими и упругими характеристиками [7,8].

Одна из важных областей применения армированных композитов на основе полимеров - трибология. Существует широкий ассортимент втулок и подшипников из различных видов армированных пластиков на основе произвольно ориентированных или однонаправленных ПКМ. Как правило, армирующие волокна эффективны для уменьшения износа в дополнение к увеличению прочности и жесткости [1]. Еще в работе [9] для нескольких пластиков, армированных волокном, было показано, что износ композиционных материалов происходит за счет истончения армирующих волокон, последующего разрушения волокон и отслаивания волокон от матрицы.
В этой работе также показано, что модуль Юнга и прочность на межслоевой сдвиг армированных волокном пластиков являются определяющими факторами, влияющими на удельную скорость износа.

В целом это означает, что современные многоуровневые композиты должны иметь лучшие трибологические характеристики из-за более высокой адгезии полимер-волокно, прочности и вязкости таких материалов по сравнению с традиционными пластиками. Поэтому в настоящей работе поставлена задача изучения основных закономерностей трения и износа углепластиков, дополнительно наполненных 1, 2 и 4 mass\% фуллереновой сажи, а также взаимосвязи исследованных трибологических характеристик с механическими свойства полученного материала.

В качестве исходных материалов были использованы углеродное волокно SYT45 (12K) производства Zhongfu Shenying Carbon Fiber Co., Ltd. (КНР), порошок полиамида 12 (ПА-12) Innova'PA 1550 дисперсностью 40-50 $\mu \mathrm{m}$ (Exceltec, Ltd.) $\left(T_{m}=185^{\circ} \mathrm{C}\right)$ и фуллереновая сажа производства Inner Mongolia Carbon Valley (КНP) (дисперсность 30-50 nm) [10]. Образцы были получены путем пропитки углеродной ленты из водных суспензий по методике, представленной в [11], с последующим компактированием методом горячего прессования. Были приготовлены образцы с добавками 0, 1, 2 и 4 mass\% фуллереновой сажи в виде прямоугольных пластин $150 \times 50 \times 1.5 \mathrm{~mm}$. Образцы для испытаний были приготовлены методом гидроабразивной резки.

Все трибологические испытания проводились в условиях сухого трения. Коэффициент трения определялся в геометрии вращения трех стальных шариков диаметром 5/16" (7.9375 mm) по плоскости с использованием реометра DHR-2 (TA Instruments) как отношение нормальной нагрузки к силе трения. 


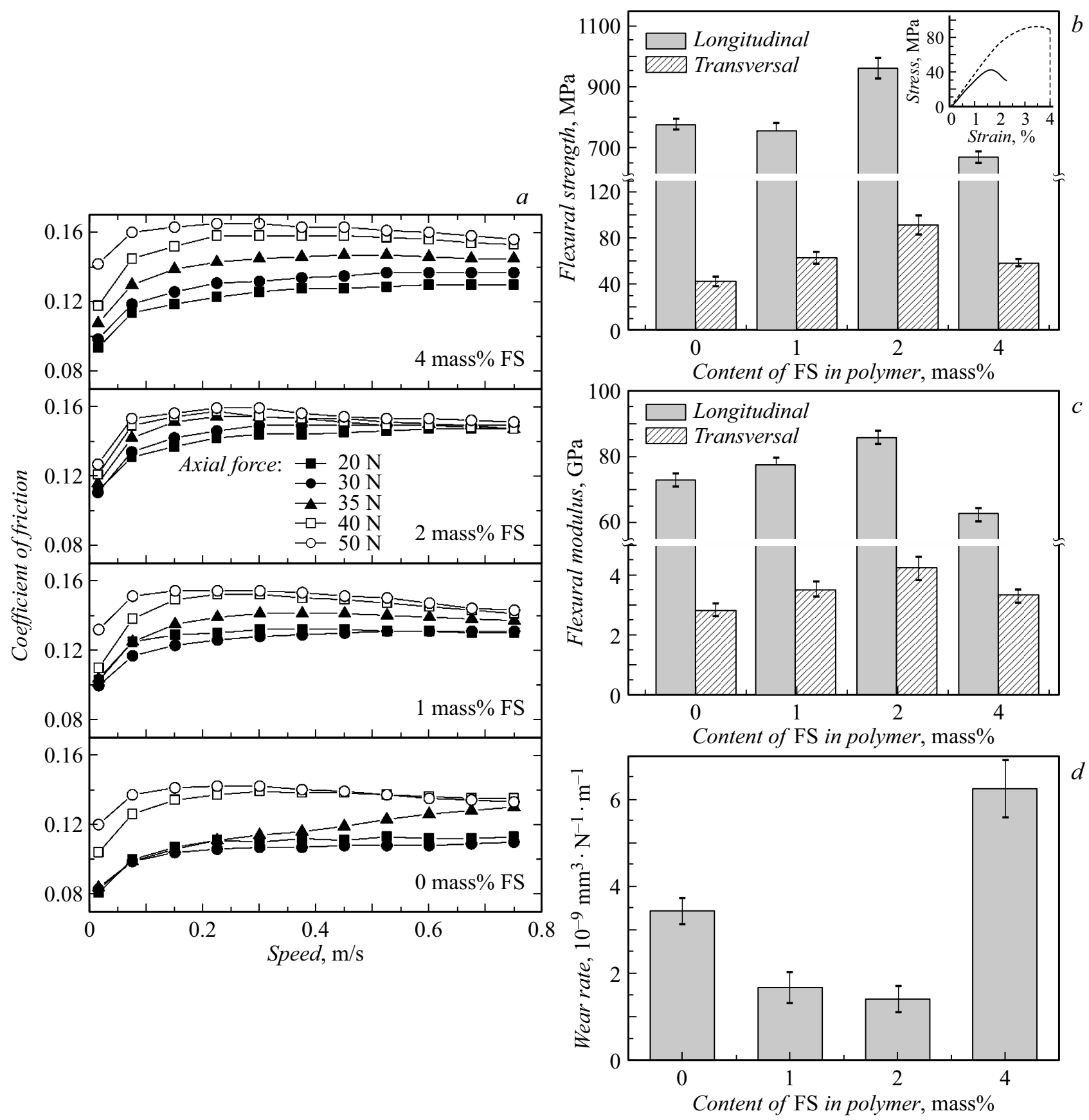

Рис. 1. Зависимости коэффициента трения $(a)$, предела прочности при изгибе $(b)$, модуля упругости при изгибе $(c)$ и скорости износа $(d)$ от содержания FS. На вставке (часть $b$ ) приведены кривые напряжение-деформация поперек оси волокна для образца с содержанием 0 (сплошная линия) и 2 mass\% FS (штриховая линия).

Износ определялся при нагрузке $80 \mathrm{~N}$ (контактное давление $0.6 \mathrm{MPa}$ ), скорости $1.9 \mathrm{~m} / \mathrm{s}$ в течение $50 \mathrm{~min}$ (путь трения $5700 \mathrm{~m}$ ) при трении кольца из нержавеющей стали с внешним диаметром $32 \mathrm{~mm}$ и толщиной стенки $1.5 \mathrm{~mm}$ по плоскости образца. Скорость износа $K$ определялась по уравнению

$$
K=m_{L} /(F S \rho),
$$

где $m_{L}-$ потеря массы, $F-$ сила, $S-$ путь трения, $\rho$ - плотность композиционного материала.
Исследования трибологических свойств вдоль и поперек волокон проводились на машине трения МТБМ [12], разработанной в Санкт-Петербургском политехническом университете, в условиях возвратно-поступательного движения шарика диаметром $12.7 \mathrm{~mm}$ по плоскости со скоростью $0.006 \mathrm{~m} / \mathrm{s}$ при варьировании нагрузки от 30 до $90 \mathrm{~N}$, общий путь трения $0.72 \mathrm{~m}$. При этих испытаниях непрерывно фиксировалась сила трения.

На рис. 1, a показана зависимость коэффициента трения от скорости и нагрузки при различном содержании 
фуллереновой сажи (FS). При увеличении содержания фуллереновой сажи до 4 mass\% коэффициент трения увеличивается в среднем от 0.09 до 0.14. Для образца с содержанием FS 2 mass\% наблюдается минимальный разброс значений коэффициента трения в зависимости от скорости и нагрузки трения: при скорости $0.5 \mathrm{~m} / \mathrm{s}$ отклонение от среднего значения не превышает 10\%. Износостойкость образцов с содержанием 1 и 2 mass\% FS увеличивается более чем в 2 раза по сравнению c износостойкостью исходного образца без добавок (рис. $1, d)$. При увеличении содержания FS до 4 mass\% увеличиваются абсолютная величина и разброс значений коэффициента трения, а также существенно уменьшается износостойкость композиционного материала.

Исследование механических свойств показало, что добавки 1 и 2 mass\% FS приводят к увеличению как модуля упругости и прочности образцов при изгибе, так и деформации до разрушения. Однако в то время как вдоль волокон эти характеристики увеличиваются незначительно (не более чем на 20\%) (рис. 1, $b, c$ ), в поперечном направлении прочность возрастает более чем в 2 раза по сравнению с таковой для исходного образца без добавок (вставка на рис. 1, $b$ ). Абсолютное значение прочности достигает $90 \mathrm{MPa}$ при существенном увеличении пластичности. Такое поведение свойств материала в поперечном направлении может быть объяснено только существенным повышением адгезии полимер-волокно в присутствии наноуглеродных добавок [2]. При увеличении содержания FS до 4 mass\% прочностные характеристики материала падают, что коррелирует с уменьшением износостойкости материала.

Однако такое поведение механических и трибологических свойств не объясняет увеличение коэффициента трения при увеличении содержания FS в матрице композиционного материала. Поэтому нами были также проведены трибологические испытания в условиях возвратно-поступательного движения вдоль и поперек волокон. Линейная экстраполяция экспериментальных данных представлена на рис. 2. Очевидно, что в присутствии FS зависимость силы внешнего трения $\left(F_{f}\right)$ от нормальной нагрузки $(N)$ описывается не законом Амонтона-Кулона

$$
F_{f}=f N
$$

а уравнением прямой типа $y=a x+b$ при $b \neq 0$, что соответствует двучленной формуле трения, предложенной академиком Дерягиным [1]:

$$
F_{f}=f N+f p_{0} A_{r},
$$

где $f-$ мгновенный коэффициент трения, $A_{r}-$ фактическая площадь контакта, $p_{0}$ - удельная сила молекулярного притяжения, действующая на участках фактической площади контакта. Формула (3) является молекулярно-физической интерпретацией [13] двучленного закона Амонтона-Кулона и при экспериментальных исследованиях часто записывается в виде

$$
F_{f}=f\left(N+N_{0}\right)
$$

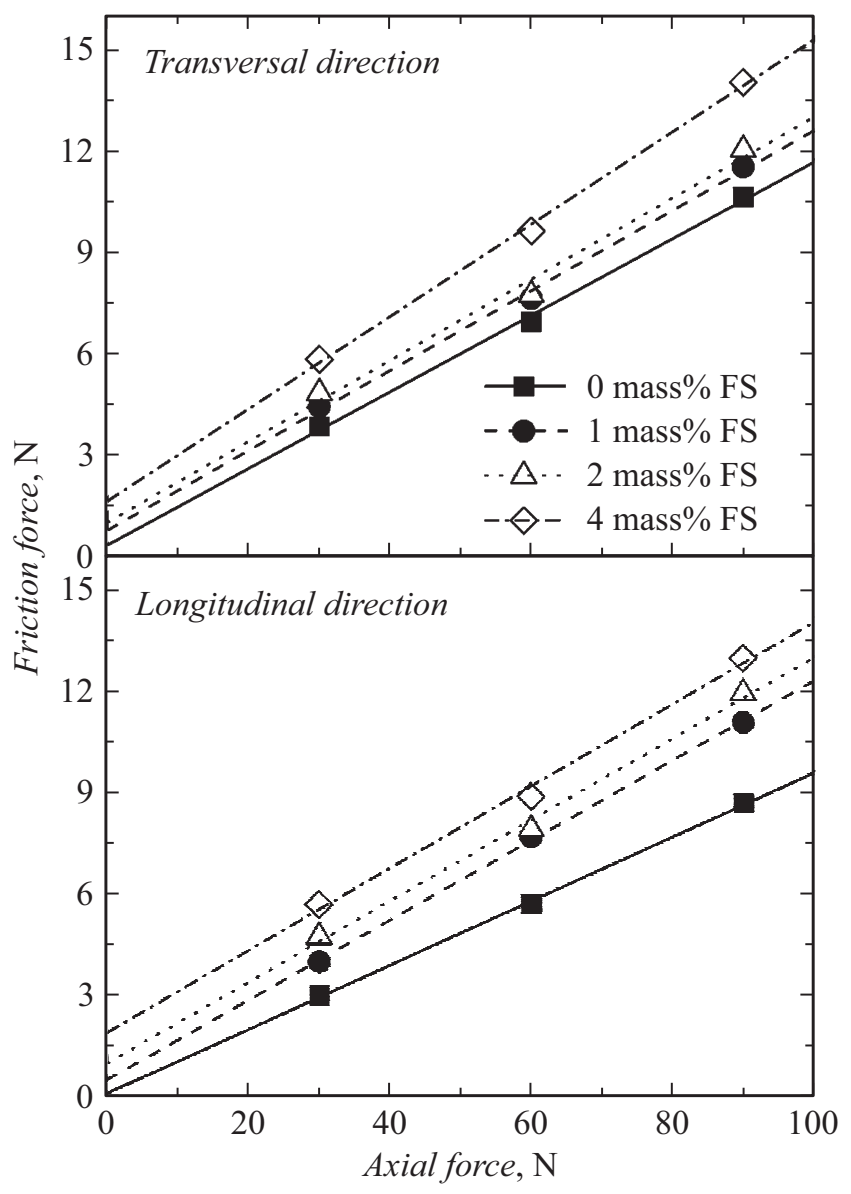

Рис. 2. Аппроксимация экспериментальных результатов при трении в режиме возвратно-поступательного движения в продольном и поперечном направлениях.

где $N_{0}$ - равнодействующая сил молекулярного притяжения тел в процессе трения. При пренебрежимо малом значении равнодействующей сил молекулярного притяжения можно принять $N_{0}=0 \mathrm{~N}$, а закон [14] перейдет в закон Амонтона (2). Полученные результаты экстраполяции представлены в таблице.

Данные таблицы показывают, что в целом при наполнении матрицы из ПА-12 наночастицами FS коэффициент трения фактически не меняется в пределах погрешности эксперимента. Увеличение силы трения происходит за счет сил межмолекулярного притяжения, равнодействующая которых увеличивается при увеличении содержания фуллереновой сажи. Наблюдаемый эффект может быть связан с большей поверхностной энергией композита с наночастицами, чем в случае исходного материала, что существенно повышает не только адгезию полимер-волокно, но и адгезию между поверхностью композиционного материала и стальным контртелом.

При рассмотрении поверхности трения композиционного материала (рис. 3) видно, что при содержании FS 0 и 4 mass \% в композиционном материале происходит 

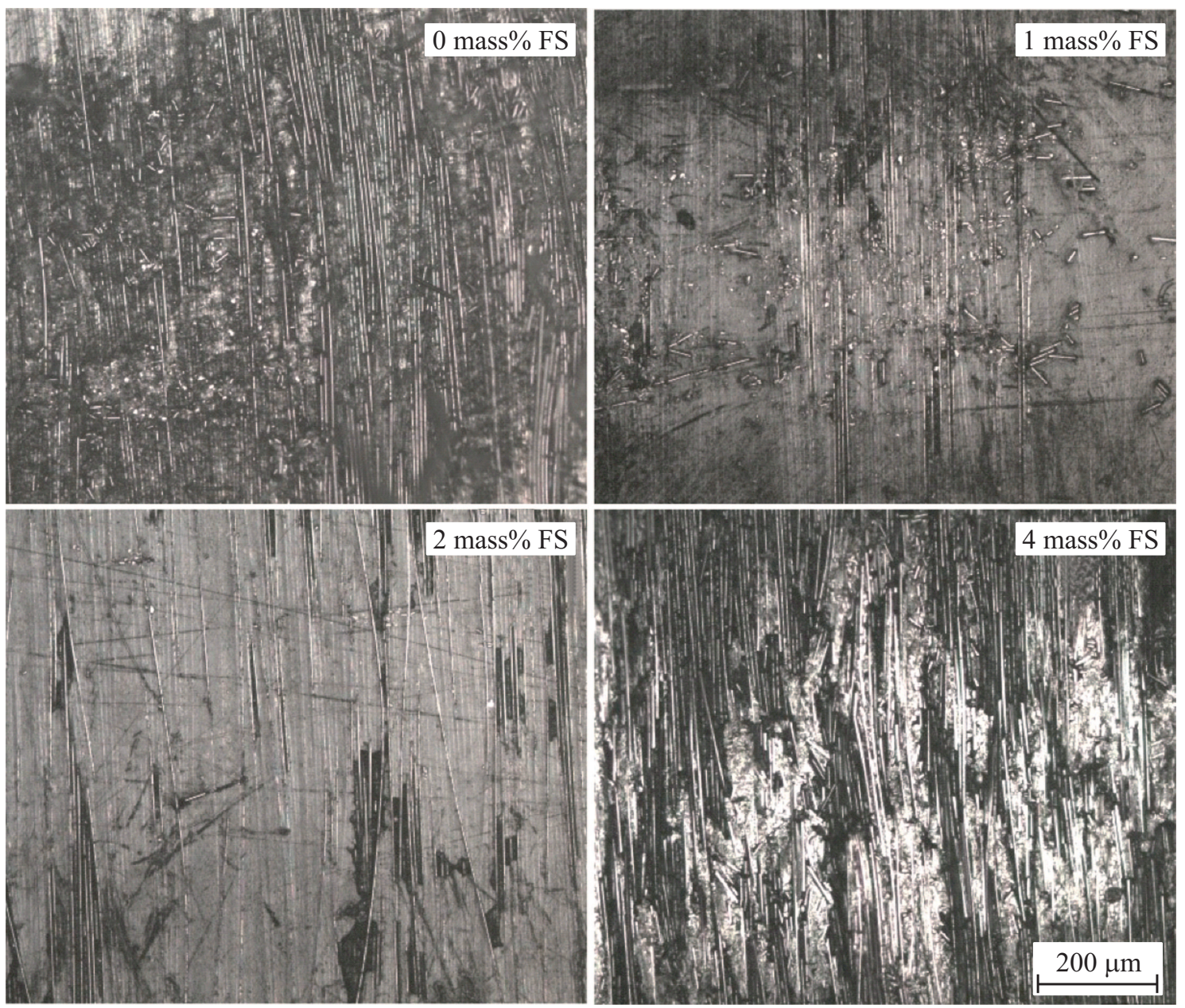

Pис. 3. Оптические снимки микроструктуры материала после трения.

Результаты экстраполяции данных в виде уравнения $F_{f}=f\left(N+N_{0}\right)$

\begin{tabular}{c|c|c|c|c}
\hline $\begin{array}{c}\text { Содержание } \\
\text { сажи } C, \text { mass } \%\end{array}$ & $f$ & $\Delta f$ & $N_{0}$ & $\Delta N_{0}$ \\
\hline & \multicolumn{4}{|c}{ Вдоль волокон } \\
0 & 0.097 & 0.003 & 0.0 & 2 \\
1 & 0.118 & 0.002 & 4.2 & 1.7 \\
2 & 0.120 & 0.008 & 8.2 & 4.4 \\
4 & 0.121 & 0.008 & 15.8 & 5 \\
& \multicolumn{4}{|c}{ Поперек волокон } \\
0 & 0.113 & 0.005 & 2.6 & 3.5 \\
1 & 0.118 & 0.006 & 5.9 & 3.4 \\
2 & 0.12 & 0.01 & 8 & 5.8 \\
4 & 0.136 & 0.006 & 11.7 & 2.9
\end{tabular}

разрушение полимерной матрицы и связанное с ним разрушение волокон композиционного материала, что ведет к увеличению результирующей силы и коэффициента трения. В образцах, содержащих 1 и 2 mass\% FS, углеродные волокна разрушаются значительно меньше.
Можно заключить, что наблюдаемый эффект постепенного повышения механических характеристик и износостойкости ПКМ с увеличением концентрации наночастиц до порогового значения ( 2 mass $\%)$ и их последующего снижения может быть объяснен наличием двух конкурирующих механизмов. Первый механизм связан с увеличением адгезионной прочности между полимером и углеродными волокнами, инициированным наночастицами фуллереновой сажи. Второй механизм связан со снижением когезионной прочности полимерной матрицы вследствие введения наночастиц. При введении в полимер относительно небольших концентраций FS (до 2 mass \%) увеличение адгезионной прочности между компонентами происходит более интенсивно, чем снижение когезионной прочности полимера. Дальнейшее увеличение концентрации наночастиц приводит к столь значительному снижению когезионной прочности полимера, что происходит снижение прочностных и трибологических характеристик всего композиционного материала в целом.

В наполненных наноуглеродом композиционных материалах коэффициент трения как (безразмерная) отно- 
сительная величина, показывающая скорость роста силы трения при приращении нормальной нагрузки, несколько увеличивается за счет увеличения равнодействующей сил межмолекулярного притяжения, что в целом увеличивает суммарную силу трения по сравнению таковой для исходного материала. При добавках до 2 mass\% FS в полимерную матрицу в условиях сухого трения наблюдается наиболее равномерное трение и минимальный износ; в таком образце не происходит разрушения волокон при трении. Установлено, что добавки 1 и 2 mass\% фуллереновой сажи приводят к увеличению прочностных характеристик и модуля упругости при изгибе материала как в продольном, так и в поперечном направлении при более чем двукратном увеличении износостойкости композиционного материала. При дальнейшем увеличении содержания FS (до 4 mass\%) происходит охрупчивание полимерной матрицы, ее разрушение на поверхности трения, сопровождаемое разрушением углеродных волокон, и связанное с этим увеличение износа и коэффициента трения.

\section{Финансирование работы}

Исследование выполнено при финансовой поддержке Российского фонда фундаментальных исследований в рамках научного проекта № 19-33-90264.

\section{Конфликт интересов}

Авторы заявляют, что у них нет конфликта интересов.

\section{Список литературы}

[1] B. Suresha, G. Chandramohan, P. Samapthkumaran, S. Seetharamu, S. Vynatheya, J. Reinforced Plast. Composit., 25 (7), 771 (2006). DOI: 10.1177/0731684406063540

[2] S. Storck, H. Malecki, T. Shah, M. Zupan, Composites B, 42 (6), 1508 (2011). DOI: 10.1016/j.compositesb.2011.04.039

[3] R. Izadi, E. Ghavanloo, A. Nayebi, Physica B, 574, 311636 (2019). DOI: 10.1016/j.physb.2019.08.013

[4] U. Tayfun, Y. Kanbur, U. Abaci, H.Y. Guney, E. Bayramli, Composites B, 80, 101 (2015).

DOI: $10.1016 /$ j.compositesb.2015.05.013

[5] T. Ogasawara, Y. Ishida, T. Kasai, Composit. Sci. Technol., 69 (11-12), 2002 (2009).

DOI: 10.1016/j.compscitech.2009.05.003

[6] S. Das, S. Halder, N.I. Khan, Mater. Today: Proc., 18 (3), 655 (2019). DOI: 10.1016/j.matpr.2019.06.461

[7] T. Saotome, K. Kokubo, S. Shirakawa, T. Oshima, H.T. Hahn, J. Composite Mater., 45 (25), 2595 (2011). DOI: $10.1177 / 0021998311416682$

[8] A. Kausar, Fullerenes Nanotubes Carbon Nanostruct., 25 (2), 109 (2017). DOI: 10.1080/1536383X.2016.1265513

[9] T. Tsukizoe, N. Ohmae, Fibre Sci. Technol., 18 (4), 265 (1983). DOI: 10.1016/0015-0568(83)90021-0

[10] E.V. Bobrynina, T.V. Larionova, T.S. Kol'tsova, Y. Zhang, X. Liang, O.V. Tolochko, Met. Sci. Heat Treatment, 62 (1-2), 70 (2020). DOI: 10.1007/s11041-020-00514-3
[11] I. Kobykhno, D. Honcharenko, V. Yadykin, O. Stolyarov, O. Tolochko, MATEC Web of Conf., 245, 04011 (2018). DOI: $10.1051 /$ matecconf/201824504011

[12] A. Breki, M. Nosonovsky, Appl. Phys. Lett., 113 (24), 241602 (2018). DOI: $10.1063 / 1.5064820$

[13] Б.В. Дерягин, Н.А. Кротова, В.П. Смилга, Адгезия твердых тел (Наука, М.,1973).

[14] Б.И. Костецкий, Н.Ф. Колесниченко, Качество поверхности и трение в машинах (Техника, Киев, 1969). 